\title{
LOS LÍMITES SEPTENTRIONALES DEL IMPERIO INCA Y EL QHAPAQ ÑAN VISTOS DESDE LA ARQUEOLOGÍA Y LA HISTORIOGRAFÍA DEL SUR ANDINO DE COLOMBIA ${ }^{1}$
}

\author{
THE NORTHERN LIMITS OF THE INCA EMPIRE AND THE QHAPAQ NAN \\ FROM THE PERSPECTIVE OF THE ARCHAEOLOGY AND HISTORIOGRAPHY \\ OF THE SOUTHERN ANDES OF COLOMBIA
}

Alejandro Bernal Vélez $z^{2,3}$

\begin{abstract}
El artículo presenta una discusión sobre el papel de los caminos y las rutas de comunicación como elementos imprescindibles en la producción social del espacio, y sobre la conformación de una región de frontera del Tawantinsuyu en el norte de los Andes en el momento de la conquista española. La información arqueológica e historiográfica disponible sobre el departamento de Nariño en Colombia y de la provincia de Carchi en Ecuador es usada con el fin de evaluar el grado de conquista y dominio de los Incas en los Andes Septentrionales, y la función de la interacción social en la configuración espacial. En el texto se resalta que, independiente del hecho de si la región hacía parte del imperio Inca, algunos elementos que se consideran característicos del llamado "mundo andino" están presentes en el registro arqueológico, e incluso que algunos de estos no se relacionan temporalmente con la presencia imperial en el sector.
\end{abstract}

Palabras claves: Andes colombianos, Qhapaq Ñan, producción social del espacio, interacción social, frontera del Imperio Inca.

The aim of this article is to discuss the role of roads and communication routes as essential elements in the social production of space, and in the conformation of a border Tawantinsuyu region in the northern Andes at the time of the Spanish conquest. Available archaeological and historiographical information on the department of Nariño in Colombia and the province of Carchi in Ecuador is used to evaluate the degree of conquest and dominion of the Incas in the Northern Andes, and the function of social interaction in the spatial configuration. The text highlights that, regardless of whether the region was part of the Inca Empire, some elements that are regarded as characteristic of the so-called "Andean world" are present in the archaeological record, and even that some of them are not temporarily related to the imperial presence in the area.

Key words: Colombian Andes, Qhapaq Nan, social production of space, social interaction, border of the Inca Empire.

En Colombia, la arqueología, la antropología y la historiografía tienen una escasa relación con las discusiones académicas sobre el pasado prehispánico de otros países andinos. Probablemente, el desinterés se deba a la ausencia en el territorio colombiano de algunas de las características geográficas de los Andes Centrales, la inexistencia de sociedades estatales precolombinas, y en particular con el hecho que en ninguna región de los andes colombianos se presentó algún tipo de control por parte de los Incas. Adicionalmente, por décadas se ha tomado como un hecho indiscutible la pertenencia de las tierras altas de Colombia al Área Intermedia y al Área Circumcaribe, y que eso las excluye de las discusiones sobre las sociedades andinas. A lo sumo, las sociedades serranas colombianas son clasificadas como "sub-andinas" (Reichel-Dolmatoff 1977). Tal vez por estas razones, en el medio académico colombiano el asunto que se entrara dentro del proceso de nominación del Camino Principal Andino como patrimonio mundial ante la UNESCO se recibió con escepticismo.

La existencia de una red de vías y rutas camineras en el sur andino de Colombia que pueden tener una considerable profundidad histórica, y que estuvieron posiblemente conectados o relacionados con el tramo septentrional del Qhapaq Ñan en la sierra norte de Ecuador, se tomaron como el componente colombiano que hizo parte del proceso de nominación (Cortez 2014; Groot y Villada 2009; Leguizamón et al. 2019;

\footnotetext{
${ }^{1}$ Una primera versión de este trabajo fue presentada en el Qhapaq Ñan II, Taller Internacional en torno al Sistema Vial Inkaico (24-27 de octubre de 2017), efectuado en Salta, Argentina. Este manuscrito fue evaluado por pares externos y editado por el Comité Editorial de Chungara y los editores invitados Carlos González y Christian Vitry.

${ }^{2}$ Universidad Nacional del Centro de la Provincia de Buenos Aires, Olavarría, Argentina.

${ }^{3}$ Equipo de Arqueología Campo La Cira - Infantas, Barrancabermeja, Colombia. albernalvel@gmail.com
} 
Universidad de Nariño 2010). La inclusión de estos caminos como parte del "Camino del Inca" no ha implicado de ninguna manera una aceptación tácita de la pertenencia de los andes meridionales del país al Tawantinsuyu. Sin embargo, en lo que respecta a Colombia, el proceso de investigación y documentación sobre el Qhapaq Nan y los valores históricos que éste representa ha resaltado la necesidad de volver a considerar el tipo de relaciones sociales y culturales que en el pasado prehispánico se dieron entre el sur serrano de su actual territorio nacional y otras regiones de los Andes, así como la profundidad histórica de dichas conexiones. Igualmente, el proceso ante UNESCO ha implicado que se tome a los caminos como partes imprescindibles en la construcción de territorios y relaciones entre regiones y comunidades.

El siguiente artículo presenta una síntesis de los argumentos, ideas y datos sobre el pasado prehispánico de los Andes meridionales de Colombia con el fin de contribuir a la discusión del tipo de presencia incaica que se dio en esta región, centrándose en la idea de la construcción de las fronteras como espacios. Se propone que en el momento de la conquista española esta porción del norte de los Andes hizo parte de un espacio que podría llamarse el "límite de la frontera" del imperio Inca. Igualmente, desea aportar a las reflexiones sobre la articulación en tiempos prehispánicos de las sociedades y territorios del sur andino del país con un conjunto geográfico e histórico más amplio llamado los Andes Septentrionales. Se plantea que estas relaciones se manifiestan de varias maneras y con distintas materialidades, y que existieron varios siglos antes de la presencia incaica en la sierra norte de Ecuador. Si bien se hará constante mención al Camino Principal Andino o Qhapaq Ñan, el interés del escrito no está dirigido a exponer detalles de las características arqueológicas de los tramos del mismo que entraron en la declaratoria de la UNESCO. Las vías y los caminos son tomados como elementos importantes para la construcción social del espacio y como agentes materiales que facilitaron la interacción social y la relación entre diferentes grupos.

En términos de los territorios nacionales contemporáneos, el área de interés del artículo se encuentra en ambos márgenes de la actual línea divisoria binacional en los altiplanos del departamento de Nariño en el suroccidente de Colombia y la provincia de Carchi en el norte de Ecuador, y en donde se ubican las actuales ciudades de Tulcán, Ipiales y Pasto (Figura 1). En épocas prehispánicas eran los territorios de los grupos étnicos llamados por los españoles Pasto en el sur, en los altiplanos de Carchi e Ipiales irrigados por los ríos ChotaMira y Guáitara, y los Quillacinga en el nororiente del Guáitara y la vertiente oriental de la cordillera.

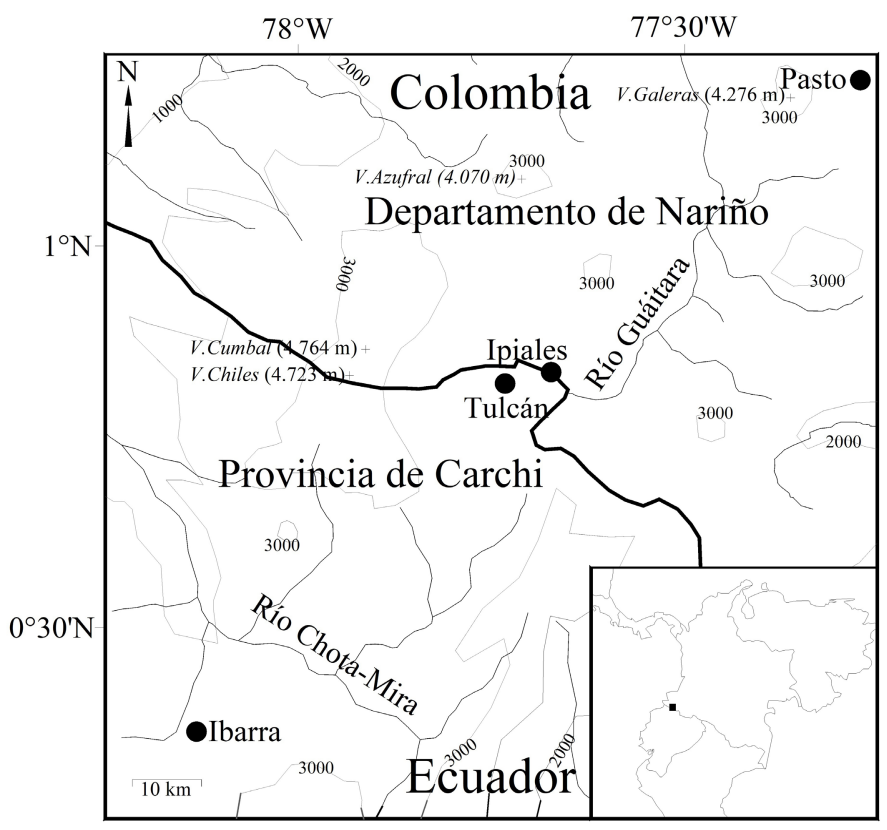

Figura 1. Ubicación de la región de estudio. Elaborada por Alejandro Bernal Vélez.

Location of the study region. Prepared by Alejandro Bernal Vélez. 


\section{El Espacio, los Límites y la Frontera como Conceptos}

Las palabras "frontera", "límite" y "espacio" se entienden en un contexto histórico y social, asumiendo que existe una "producción social del espacio". Como lo han expresado algunos autores (Criado 1991:7; Lefebvre 1974:226), la expresión hace alusión a un conjunto amplio de dinámicas sociales, políticas, culturales y simbólicas que le dan sentido a un terreno, área, superficie, etc. De esta manera, hablar de "espacio" es referirse a una entidad creada por la acción humana. Las acciones sociales, culturales o productivas no se dan sobre el espacio como si este fuera una realidad ajena y separada. Son precisamente aquellas cuestiones las que crean y dan uno o varios sentidos a un espacio determinado.

Siguiendo con la idea que lo espacial se debe entender ante todo como un sistema dinámico, las divisiones que separan territorios y personas son entidades creadas por la cultura, la política y las relaciones sociales, y por tanto están en una permanente construcción. Los límites espaciales no se pueden tomar como líneas rígidas e impermeables que están dispuestas en hitos físicos como un río o una montaña (Ramírez de Jara 1996:71). Aun cuando se fija una línea fronteriza, detrás de dicho proceso existe una "horogénesis", es decir, que una frontera es el producto de una evolución histórica y del proceso de inscripción en el tiempo y el espacio de un conjunto de divisiones políticas, culturales y sociales que afirman discontinuidades y marcan transiciones en terrenos que, en ocasiones, presentan ciertos rasgos de homogeneidad y continuidad (Deler 1996:24).

En varios textos (Bray 2018; Bray y Echeverría 2014; Caillavet 2000a; Dillehay y Netherly 1998; Hyslop 1998; Morris 1998; Salomon 1980, 1988, 1998) se argumenta que los procesos de expansión de las fronteras del estado Inca se dieron en realidades geográficas diversas e involucrando una multiplicidad de estrategias de relación con las sociedades locales. Adicionalmente, proponen que este proceso fue gradual, no homogéneo, e involucró un proceso de adaptación, negociación y resistencia mutua entre "conquistador" y "conquistado". Estos argumentos traen también la idea que los límites del Tawantinsuyu configuraron espacios fronterizos más que una serie de líneas específicas que definían o demarcaban el territorio bajo su control. En este sentido, la interacción de los incas con otros grupos y territorios que les eran ajenos, así como las prácticas y dinámicas socioculturales, políticas y económicas que generaron estas relaciones de poder, fue lo que creó espacios de frontera en distintos lugares de los Andes.

Así mismo, los espacios de frontera en el mundo andino creados por las dinámicas de la expansión incaica no presentaron una uniformidad en su interior. Por un lado, según Dillehay y Gordon (1998:183), pudieron existir al menos dos situaciones de frontera vistas desde el interior del Estado Inca. En primer lugar, aquellas relaciones sociales y espaciales dentro de una "frontera geopolítica exclusiva" ocupada militarmente y formalizada mediante una mayor presencia institucional del incario. Coinciden con la distinción que en su momento hizo Hyslop (1998:33-35) de espacios fronterizos de "dominación segura". En segunda instancia, una "frontera geopolítica inclusiva" más externa, y que formaba un "archipiélago" de variadas actividades estatales dispersas (Dillehay y Gordon 1998:183). Estos espacios fronterizos externos pueden definirse también como "territorios insulares fragmentados" y de naturaleza esparcida, donde el control que buscó o intentó el Estado no se manifestó de una manera continua en las regiones, ni el control territorial fue homogéneo (Dillehay y Netherly 1998:19). Esto pudo deberse, posiblemente, a que los recursos estratégicos en los Andes, y cuyo acceso buscaron los incas en casi todas las ocasiones, están dispuestos en franjas y zonas ecológicas dispersas y no contiguas dentro los territorios de las unidades políticas que el Tawantinsuyu buscó dominar o al menos incorporar (Morris 1998:106).

Al momento de la conquista española en la década de 1530, la región del extremo norte de la sierra ecuatoriana y los andes meridionales colombianos que le eran contiguos presentan algunos elementos que recuerdan esta segunda situación de espacios fronterizos, así como otros que ratificarían que los territorios de los grupos Pasto y Quillacinga se ubicaban en los límites más externos de la frontera boreal del Tawantinsuyu en los Andes Septentrionales (Figura 2). Dentro de esta contextualización de los espacios fronterizos norandinos, las rutas y redes camineras ubicadas en el sur del departamento de Nariño y que fueron propuestos como partes del Qhapaq Nan, estarían por fuera de las fronteras de "dominación segura" que refirió Hyslop (1998) y harían, posiblemente, parte de espacios en donde pudo haberse dado de manera fragmentada, ocasional, y ciertamente efímera, algún tipo de presencia incaica (Figura 3).

\section{El Sur de los Andes Colombianos como Espacio Geográfico y Social}

Diversos autores han categorizado la variabilidad ecológica y geográfica de la cordillera de los Andes y las particularidades de los andes colombianos (Dollfus 1981; Guhl 1975; Parsons 1982; Troll 1958). En aras de resumir las características de las sierras andinas del sur de Colombia y del norte de Ecuador, estas se encuentran sobre la línea equinoccial, y están flanqueadas por dos frentes muy húmedos: uno al oriente, en la Amazonía, y otro al occidente desde del cual llega la influencia del Pacífico del norte de Suramérica. Dado que en Ecuador y Colombia la cordillera de los Andes tiene una altitud promedio menor que los Andes Centrales, con muy 


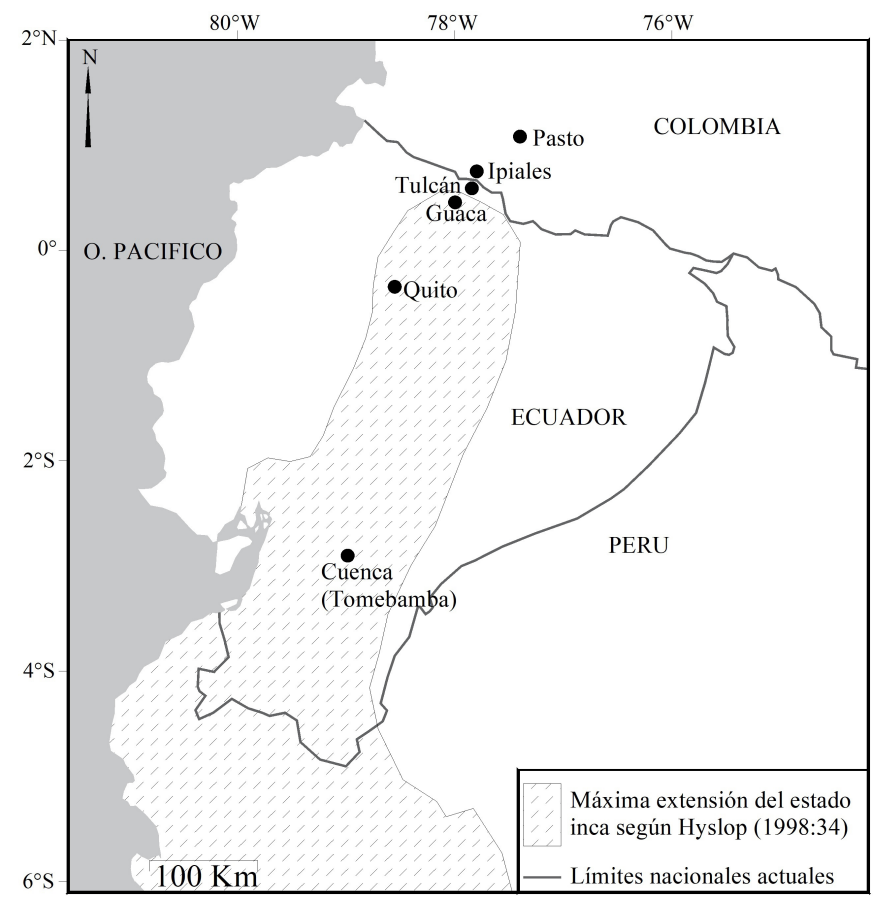

Figura 2. Los límites del Estado Inca. Elaborado por Alejandro Bernal Vélez a partir del mapa de Hyslop (1998:34).

The limits of the Inca State. Prepared by Alejandro Bernal Vélez from the map of Hyslop (1998:34).

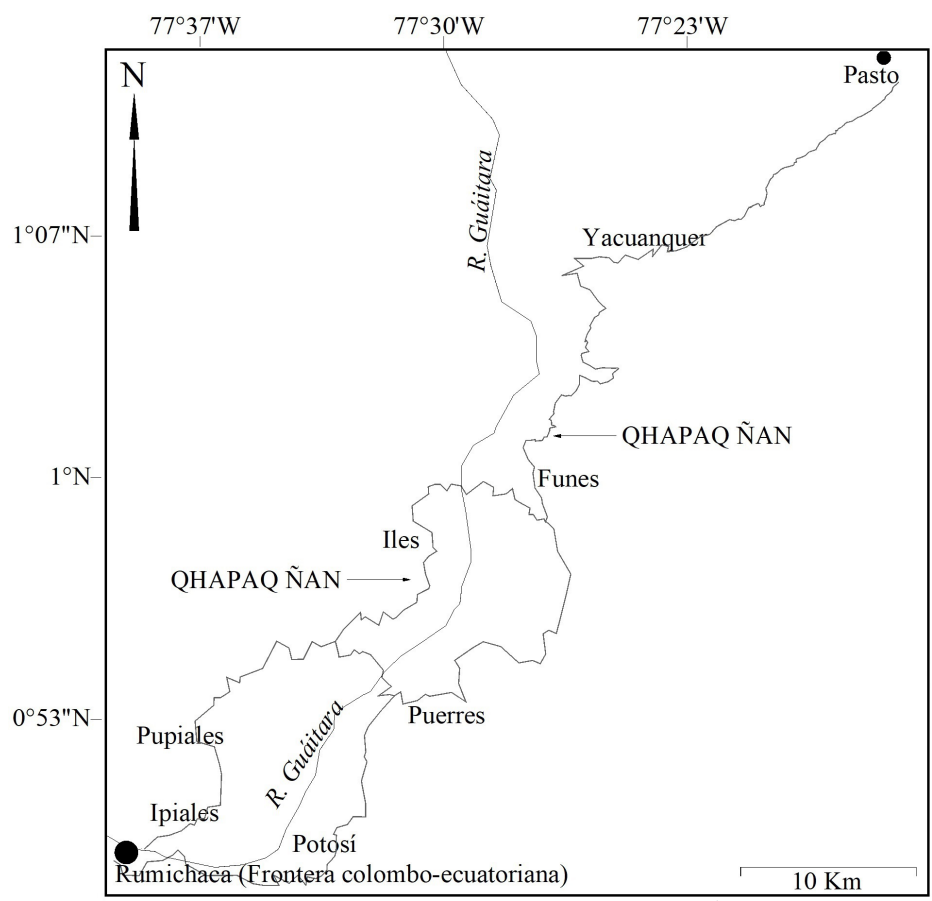

Figura 3. Ubicación del tramo colombiano del Qhapaq Ñan. Elaborada por Alejandro Bernal Vélez a partir de la información suministrada por el Equipo del Qhapaq Ñan Colombia de la Universidad de Nariño.

Location of the Colombian section of the Qhapaq Ñan. Prepared by Alejandro Bernal Vélez from the information provided by the Qhapaq Nan Colombia Team of the University of Nariño. 
pocos y discontinuos macizos de gran altura que superen los 4.500 o $5.000 \mathrm{msm}$, y que son considerablemente más angostos en comparación a los Andes de Perú y Bolivia, los vientos cargados de humedad de ambos costados pasan fácilmente, determinando que los Andes Septentrionales sean espacios predominantemente húmedos con algunos econichos secos circunscritos generalmente a cañones y valles interandinos.

Otra característica del norte de los Andes es la presencia de cinco franjas altitudinales dispuestas verticalmente y que son llamadas "pisos térmicos" (Dollfus 1981) (Figura 4). Ordenados de mayor a menor altitud estos serían: Nieves perpetuas y glaciares en alturas superiores a los $4.500 \mathrm{msm}$. Páramos desde los $3.000 \mathrm{o}$ $3.200 \mathrm{msm}$ y caracterizados por su escasa insolación y elevada pluviosidad. El piso térmico "frío" desde los $2.00002 .200 \mathrm{msm}$ con temperaturas que oscilan entre los $0{ }^{\circ} \mathrm{C}$ y los $20^{\circ} \mathrm{C}$, e igualmente marcadas por la constante nubosidad y periodos prolongados de lluvias. Tanto los páramos como el piso "frío", son característicos de los corredores interiores andinos. Por último, los pisos de las "tierras templadas" y "calientes" desde los 1.000 y 0 msm respectivamente, y con niveles de temperaturas más cálidas. Estos sectores están tanto en los flancos externos de la cordillera como en los valles interandinos.

Lo importante de retener de estas características geográficas y climáticas de los Andes Septentrionales es que configuran un variado mosaico de sistemas ecológicos, tanto de vertientes como de montaña y alta montaña, que están muy próximos entre sí y que han sido integrados cultural, social, económica y políticamente de diferentes maneras por las comunidades y grupos étnicos que ahí se han asentado. Al menos en lo que respecta a tiempos prehispánicos, una de las diferencias entre la puna y el páramo como espacios culturales y sociales, es que en este último ni se desarrollaron actividades económicas como la agricultura y el pastoreo, ni se presentaron asentamientos humanos grandes, densos y permanentes (Dollfus 1981), si bien pudieron ser cotos de caza y de obtención de madera los sectores más bajos del páramo. No obstante, los páramos han ocupado un importante lugar dentro de la geografía sagrada norandina, y son hitos del paisaje desde los cuales se proyecta la construcción y ordenación del territorio de las comunidades y grupos étnicos. En especial, subyace la idea que los páramos y las cumbres de los cerros son las moradas o el lugar de origen de los "ancestros" y de otros seres míticos importantes en las cosmogonías y tradiciones orales de los pueblos (Bernand 2008; Caillavet 2000b; Mamián 1996).

En los Andes Septentrionales, el principal espacio de ocupación y de reproducción social y económica fue el piso térmico "frío". Los altiplanos de Carchi y Nariño son un ejemplo de la ocupación prehispánica, colonial y actual de los lugares "fríos" (Calero 1991; Landázuri 1995; López 1996; Mamián 1996; Uribe 1977-78). Muy importante de mencionar son las relaciones sociales y culturales de la "tierra fría" con

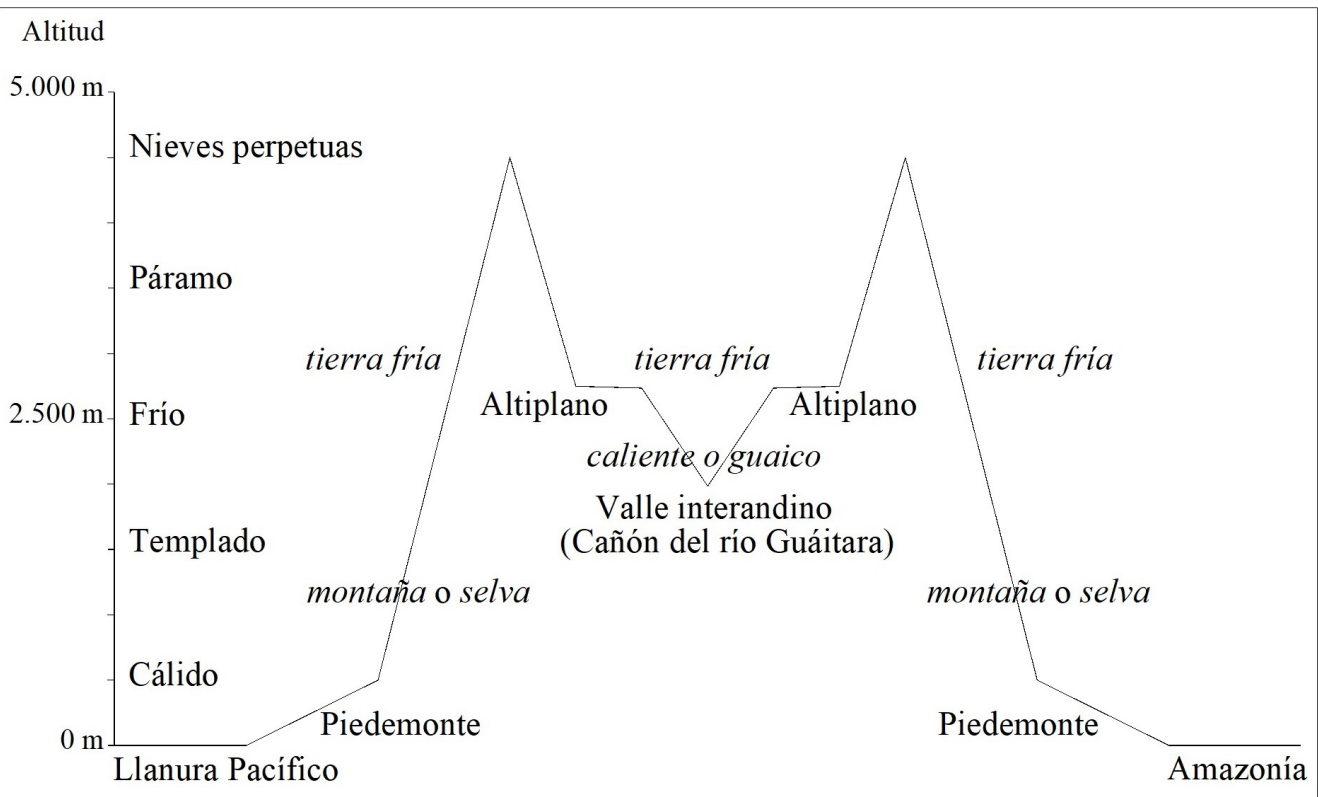

Figura 4. Esquema espacial de Los Andes del departamento de Nariño. Elaborada por Alejandro Bernal Vélez.

Spatial scheme in the Andes in the department of Nariño. Prepared by Alejandro Bernal Vélez. 
las áreas de las vertientes externas adyacentes a las tierras bajas del Pacífico en el poniente, y a las de la Amazonía en el levante (Figura 4). Para los grupos indígenas actuales del interior andino de Nariño, los piedemontes y tierras bajas tropicales y sus habitantes representan la "montaña" y la "selva" (Ramírez de Jara 1992, 1996). Así mismo, en la cordillera de los Andes del norte ecuatoriano y sur colombiano existen cañones muy profundos dentro del callejón interandino, como es el caso de los cursos de los ríos Guáitara y Chota-Mira. En estos se presentan espacios más secos con temperaturas superiores a las de los altiplanos. Algunas de estas tierras cálidas son nombradas por las comunidades actuales indígenas y campesinas en los sectores centro y sur del departamento Nariño como el "guaico" (o "caliente"), y funcionan en oposición simbólica con lo "frío" (López 1996:247 y ss; Mamián 1996:41 y ss; Rappaport 1988b). Esta dicotomía fríocaliente, representada en los contrastes entre el altiplano y los "guaicos" interiores o la "montaña" exterior, es un importante elemento que ha estructurado el espacio en esta región, y ha puesto en contacto unidades sociales de distinto tipo, tamaño y jerarquía.

Un ejemplo de la relación entre espacios fríos y calientes en el mundo norandino es la articulación de los cultivos de tubérculos y de maíz. Los datos históricos del periodo Colonial temprano muestran, o al menos sugieren, que los pastos y otros grupos de la región, cultivaban y cosechaban ambos productos (Bernal 2000; Calero 1991; Landázuri 1995; Rodicio 1995), lo cual tiene unas implicaciones espaciales importantes. En épocas prehispánicas y coloniales tempranas, tanto las élites cacicales como el grueso de la población ocupaban durante una parte del calendario agrícola los altiplanos y partes superiores de los valles donde se observa frío y humedad. En estos sectores estaban la producción de tubérculos. En otros momentos del ciclo anual ocupaban las tierras maiceras en los cañones y fondos de los valles donde se recibe más calor y menos humedad, siendo probable que estas últimas tierras, o su producción, fueran controladas por los caciques (Landázuri 1995:64). No obstante, en la segunda mitad del siglo XVI, los encomenderos del Distrito de Pasto hacían alusión que los indios de esta jurisdicción, es decir tanto pastos como quillacingas, manejaban maíces "fríos" y "calientes" a la par de la producción de papa (Rodicio 1995), dato que puede interpretarse como una producción maicera en varios pisos térmicos, y que en la altura el maíz, seguramente un maíz "frío", era un complemento menor de los tubérculos. Aún hoy en día los campesinos e indígenas del callejón interandino nariñense tratan en lo posible de acceder tanto a tierras para la producción de maíz en sectores más cálidos, como a las de tubérculos en áreas más frías (López 1996; Mamián 1996; Rappaport 1988a, 1988b).
Arqueológicamente para esta región no se cuenta con datos sobre el origen y trayectoria del cultivo y consumo de los tubérculos, pero sí para el maíz. De este último, se ha podido registrar rastros de granos y raquis carbonizados en el altiplano de Ipiales sobre la cota altitudinal de los $3.000 \mathrm{msn}$, y con una fecha de $1.150 \pm 240$ AP (GX-23955, carbón, cal. 800 \pm 240 DC [Cavelier et al. 2019:34]). Si bien no es posible determinar que su producción sea local, en todo caso indica claramente su consumo en el piso térmico frío. De igual forma, en el cañón del Río Guáitara, en una zona de "guaico" entre Yacuanquer y Consacá, se encontraron restos carbonizados de maíz con una fecha

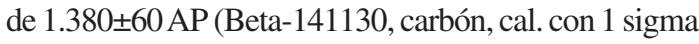
630-680 DC y dos sigmas 570-765 DC [CárdenasArroyo y Bernal 2019:198]). Otros datos arqueológicos indican la gran importancia del maíz para las prácticas sociales prehispánicas. Dentro del ajuar que componen los entierros arqueológicos de los altiplanos de Carchi e Ipiales, la aparición de ánforas y copas (Uribe 1977-78; Uribe y Lleras 1982-83) hace pensar en la valoración social que tenía la producción y consumo de la chicha como mecanismo para establecer alianzas y reafirmar lazos sociales mediante el festejo.

Esta relación de grupos y unidades sociales de las áreas "frías" con el "guaico"o "caliente" se extendía también a otros productos importantes para la reproducción biológica, social y cultural de las comunidades de las tierras altas como son la sal, el algodón y la coca. Las fuentes del periodo Colonial temprano sugieren una gran actividad humana en cocales y algodonales ubicados en laderas y fondos de los cañones de los ríos Guáitara y Chota-Mira (Bernal 2000; Landázuri 1995; Salomon 1980). Una de las consecuencias de la configuración geográfica de los Andes Septentrionales es que para las comunidades norandinas la obtención de productos de diversas ecologías dispuestas verticalmente, en especial entre altiplanos fríos y húmedos, y valles secos y cálidos, se hacía en espectros cortos de distancia dentro de territorios generalmente controlados por una sola unidad política (llámese esta un cacicazgo, una "llajta" o un "curacazgo"), fenómeno que para el caso de los Andes Septentrionales, ha recibido el nombre de "microverticaldad", así como mediante arreglos interétnicos como fue el cultivo de algunos productos en territorios controlados por otra etnia o unidad política, y por medio del intercambio con etnias y regiones vecinas (Oberem 1981).

Los datos y argumentos sobre las prácticas de intercambio y flujo de productos en la sierra norte del Ecuador y sur de Colombia han sido ampliamente documentadas desde varias perspectivas. Las evidencias arqueológicas reflejan que la interacción social entre las comunidades y territorios del callejón interandino tiene raíces muy arraigadas en el tiempo, y se prolonga en 
un espectro geográfico más amplio que los altiplanos y valles interandinos de Nariño y Carchi. La cerámica prehispánica que se considera característica de esta región, y de la cual se hará referencia más adelante, ha sido reportada en sitios al sur del Río Chota-Mira en las provincias ecuatorianas de Imbabura y Pichincha (Bray 1995; Doyón 1995; Lleras et al. 2007; Molestina 1998). En lo que tiene que ver con la metalurgia prehispánica hallada en la zona andina del departamento de Nariño, las tecnologías y materias primas usadas para la elaboración de adornos personales encuentra pocos referentes dentro de la arqueología colombiana, pero exhibe mayores relaciones con la metalurgia prehispánica del Ecuador e incluso con la de los Andes Centrales (Lleras et al. 2007:75; Plazas 1977-78:215; Uribe 1986:36).

Todos los materiales arqueológicos que se han nombrado, y que seguramente constituyeron una parte consustancial de la interacción sociocultural precolombina en esta porción de los Andes Septentrionales ubicada en la sierra norte de Ecuador y del sur de Colombia, datan de tiempos anteriores a la conquista española en la década de 1530 y la presencia inca en la zona algunos pocos decenios antes. En efecto, al menos a la luz de la cronología para la región quiteña, la temporalidad de los conjuntos cerámicos que comparten características decorativas y formales con los de los altiplanos de Carchi e Ipiales giraría alrededor del 1.600 AP (Doyón 1995:70-73). En lo que respecta a la zona nariñense, las fechas más tempranas de la cerámica se encontraron en la localidad de Jongovito, cerca de la ciudad de Pasto, y se ubicarían temporalmente en el

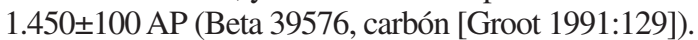

Parece ser que el acceso y obtención de productos como la coca, el algodón y la sal fueron el aliciente y el motor de los intercambios dentro de los valles y altiplanos andinos. Nótese que la configuración de los tramos del Qhapaq Nan que se han propuesto para Colombia discurren en un sentido S-SO a N-NE entre Ipiales y Pasto dentro del callejón interandino y siguiendo un trazado paralelo al curso del Río Guáitara (Figura 3 ), es decir, se pueden pensar como una estructura de comunicación en sentido longitudinal que participó en la interacción social de los grupos cordilleranos, por ejemplo, entre los pastos al sur y los quillacingas en el norte. Además, estos caminos atraviesan un gradiente de ecosistemas que oscilan entre húmedos y fríos de altiplanos ubicados entre los 2.800 o 3.000 metros de altitud y valles secos y cálidos en lugares considerados de "guaico" en el cañón del Río Guáitara en cotas inferiores a los 2.000 o 1.800 metros de altitud. En otras palabras, conectaba localidades productoras de tubérculos y maíz con posibles áreas destinadas a la coca, el algodón y otras variedades de maíz.

Igualmente, otros productos indispensables para la reproducción cultural y el mantenimiento de las relaciones de poder estimularon una interacción entre tierras altas andinas y tierras bajas amazónicas o de la llanura del Pacífico. Es decir, relaciones de tipo transversales costa pacífica-sierra-selva amazónica. María Victoria Uribe (1986:39) ha resaltado algunas posibles rutas que comunicaban el espacio interandino ocupado por los Pasto con selvas húmedas del pacífico y la Amazonía ubicadas en piedemontes y llanuras al poniente y al levante de los Andes del sur de Colombia: hacía el occidente, bordeando las laderas de los volcanes Chiles y Cumbal, y descendiendo hacia el pacífico por las cuencas de los ríos San Juan y Nulpe; mientras que el acceso al oriente se lograba por la cuenca alta del Río Chota-Mira en un paso por el pueblo de Pimampiro, bajando al piedemonte amazónico por las cuencas de los ríos Kofanes, Azuela y Dué para conectar con el Aguarico en territorio Kofán. O bien, desde Puerres, conectando con la cuenca alta del Guamués y de esta forma con el alto Putumayo, igualmente en áreas ocupadas por los kofanes.

La etnografía e historiografía de las comunidades indígenas actuales de Nariño revelan algunas de las conexiones y relaciones de intercambio tanto con las estribaciones occidentales de la cordillera (Mamián 1996; Rappaport 1988a, 1988b), como con las orientales (Gómez 1997; Ramírez de Jara 1992, 1996). La arqueología muestra que algunos elementos textiles, de madera y artículos asociados al ritual como plumas o narcóticos que se encuentran en los ajuares de las tumbas prehispánicas de los altiplanos de Nariño y Carchi fueron obtenidos por medio del intercambio con grupos de estas regiones (Uribe 1977-78, 1986; Uribe y Lleras 1982-83).

Se ha resaltado la existencia de una clase particular de mercaderes llamados "mindalaes" que se encargaban del abastecimiento de productos de procedencia lejana como la Amazonía, e incluso la costa norte del Perú, a las comunidades de los altiplanos de Carchi e Ipiales y de otras asentadas en áreas vecinas en el septentrión andino (Bernal 2000; Landázuri 1995; Salomon 1980,1988; Uribe 1986). El origen lingüístico e histórico del vocablo "mindala" o "mindalá" es aún incierto, pero con independencia de esto, lo importante de retener de la palabra es su relación con significados como "tocar camino", "cargar" y "comprar y vender comestibles" (Salomon 1980:165, 1988:115). No en vano se eligió como símbolo del proceso del Qhapaq Nan en Colombia una figura decorativa de las copas cerámicas prehispánicas de los altiplanos del sur andino colombiano que parecería corresponder a los "mindalaes" (Cortés 2014; Universidad de Nariño 2010) (Figura 5). Se puede pensar entonces que estos mercaderes que se movían por los caminos y rutas de intercambio de la región fueron actores importantes en la interacción social y la construcción social del espacio.

Por último, y como ejemplo de las reflexiones que suscita la relación de la arqueología del sur de Colombia 


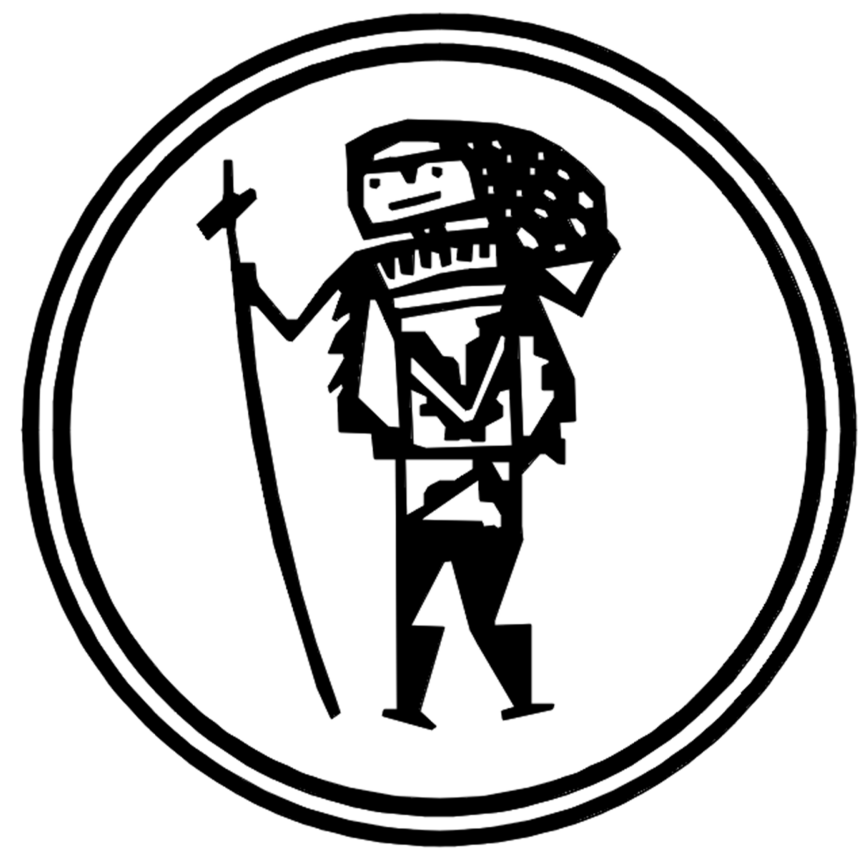

Figura 5. Posible representación de un "mindalá" en la cerámica arqueológica del altiplano de Ipiales. Elaborada por Alejandro Bernal Vélez a partir de la idea presentada en Universidad de Nariño (2010).

Possible representation of a "mindala" in the archaeological ceramics of the Ipiales plateau. Prepared by Alejandro Bernal Vélez based on the idea presented at Universidad de Nariño (2010).

con la de otras geografías andinas, vale la pena mencionar el hallazgo de textiles arqueológicos en el sur de Nariño elaborados con lana de camélidos. Por su asociación con otros elementos arqueológicos presentes en los entierros prehispánicos del sitio arqueológico de Miraflores en el altiplano de Ipiales, fueron fechados entre los siglos VII y XIII DC (700ะ35 AP (Grn-6911, carbón [Cardale de Schrimpff 1977-78:248]). Según la arqueóloga Marianne Cardale de Schrimpff (1977-78:266), los motivos decorativos y las técnicas textiles encuentran similitudes con otras industrias textiles prehispánicos andinos encontrados en Ecuador y Perú (Figura 6).

La tecnología, los estilos de hilado, trenzado y urdimbre, y en especial el hecho de ser hechas con fibra de origen animal, no tienen referentes conocidos en los Andes del centro o norte de Colombia. Inicialmente se puede pensar que llegaron al altiplano de Ipiales por medio del intercambio de larga distancia desde el centro o sur de Ecuador, o incluso del Perú. No obstante, existen algunos elementos que harían pensar en que se trata de lanas obtenidas con auquénidos presentes en la zona.

La presencia de camélidos en los Andes del centro y norte de Ecuador y del sur de Colombia es un tema del cual se tienen muy pocos datos arqueológicos e historiográficos, pero se propone que no era del todo desconocida en la región al momento de la conquista española (Bonavia 1996:383-384; Caillavet 2000c:123).
Puede ser que estos animales fueran una introducción incaica (Caillavet 2000a:166), pero algunos datos sobre la existencia de auquénidos en sitios arqueológicos del centro y norte del Ecuador rastrean su posible uso varios siglos antes de la irrupción del Tawantinsuyu (Stahl 2003:479). Mientras que los registros ecuatorianos de camélidos en la sierra norte están asociados a entierros, en lo que respecta a Colombia se tiene el registro de su ocurrencia en dos basureros arqueológicos y, por cierto, se trataría de los reportes más septentrionales de camélidos prehispánicos en toda la Cordillera de los Andes.

Nombrándolos según el orden en que fueron hallados, el primero corresponde a un sitio trabajado por Uribe (1977-78:116) en la localidad de San Luis (en la latitud $0^{\circ} 50$ 'N) y nombrado como "San Luis 2", al noroeste de la actual Ipiales. El segundo, ubicado aproximadamente a unos $5 \mathrm{~km}$ al sur del anterior (latitud $0^{\circ} 47^{\prime} \mathrm{N}$ ) en la vereda Santafé, igualmente cerca de Ipiales, y nombrado como "Corte 4" (Cavelier et al. 2019). En ambos casos se trata de yacimientos en donde los huesos de camélidos están asociados con fragmentos de una cerámica conocida como Tuza. Para el sitio de "San Luis 2" no se realizaron estudios detallados de los huesos, ni se extrajo material para fechar, pero en el análisis de los huesos del "Corte 4" de Santafé se pudo determinar que una parte significativa del material pertenece a Lama s.p, no obstante, algunas pocas piezas pudieron definirse como pertenecientes a llama (Lama 

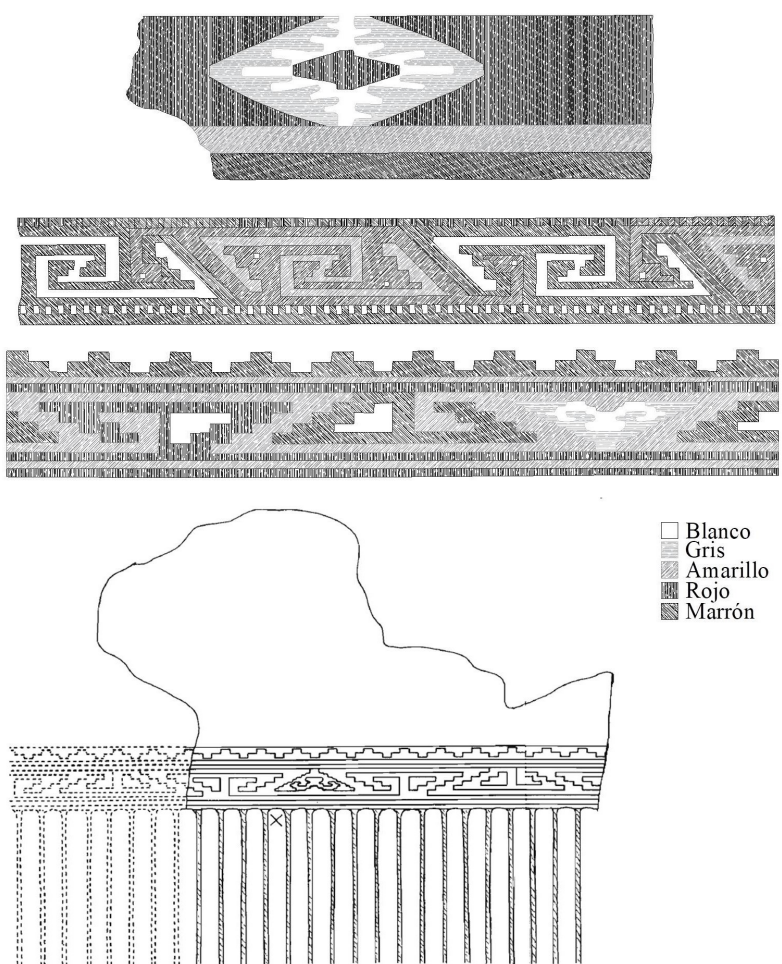

Figura 6. Decoración de los textiles nariñenses elaborados con lana de camélido. Elaborada por Alejandro Bernal Vélez a partir de los diseños y gráficas de Cardale de Schrimpff (1977-78).

Decoration of Nariño textiles made of camelid wool. Prepared by Alejandro Bernal Vélez from the patterns and graphics of Cardale de Schrimpff (1977-78).

glama) y alpaca (Lama pacos) (Cavelier et al. 2019:73; Rincón 2001:98). La fecha asociada al "Corte 4" sería de $980 \pm 180$ AP (GX-23956, carbón, cal.1.050 \pm 180 DC [Cavelier et. al 2019:34]).

Con los escasos datos conocidos es realmente muy poco lo que se puede decir sobre la presencia y uso de llamas o alpacas en el sur andino de Colombia, aparte de su posible uso en la producción textil, y que estos animales no fueron introducidos por los incas al territorio de los pastos, sospecha que por cierto ya había sido planteada por Uribe (1986:35). Puede ser que estuviesen asociados principalmente a prácticas y actividades de las élites cacicales, ya que su escasa presencia en el norte de Ecuador está relacionada en buena medida con los ajuares funerarios de ciertos individuos (Stahl 2003:472). Es particularmente intrigante lo que esto implicó en términos de la espacialidad y territorialidad de los grupos, y de llegar a determinar que había prácticas ganaderas y que no llegaron simplemente por medio del intercambio, habría que precisar cuáles eran las áreas de pastoreo y la relación espacial con los sectores cultivados.

\section{El Sur Andino de Colombia y el Tawantinsuyu: La Creación de una Frontera}

Un gran cúmulo de evidencias arqueológicas y documentales sobre la presencia incaica en la sierra norte de Ecuador y en el extremo meridional de los Andes colombianos indican que, al momento de la conquista española en la década de 1530, una dominación con algún tipo de presencia militar e instituciones estatales, no superó la margen norte del Río Chota-Mira (Bray 2003, 2018; Bray y Echeverría 2014; Caillavet 2000a; Hyslop 1998; Plaza Schuller 2006 [1976]; Romoli 1977-78). Es decir, los últimos territorios incorporados de manera relativamente efectiva en el Chinchaysuyu fueron Caranqui y Cayambe. Sin embargo, algunos datos arqueológicos e historiográficos sugieren que los incas intentaron controlar poblaciones y acceder a territorios al norte del Chota-Mira (Calero 1991; Landázuri 1995; Salomón 1980, 1988). En este sentido, los pastos se relacionaron de alguna manera con representantes del Tawantinsuyu, si bien esta relación no tuvo efectos sociales, políticos o económicos duraderos 
en el tiempo, como tampoco lo tuvo para cualquier otra región del suroccidente colombiano (Langebaek 1991).

En términos cronológicos la presencia incaica en la región se remonta al ocaso del siglo XV d.C. y las primeras décadas de la siguiente centuria, y está asociado a la figura del Inca Huayna Cápac según lo mencionan algunos cronistas como Pedro Cieza de León (2005 [1553]:447), Inca Garcilaso de la Vega (1976 [1609]:II,167) y otros mencionados en la literatura arqueológica e historiográfica contemporánea sobre la región.

Dentro del repertorio de evidencias a considerar, se podría destacar la cerámica arqueológica de los valles y altiplanos andinos del centro y sur del actual departamento de Nariño. Las discusiones arqueológicas sobre las formas de ocupación del espacio y las trayectorias de cambio socio-cultural del periodo prehispánico han gravitado sobre la existencia de tres estilos o complejos cerámicos: Capulí, Piartal y Tuza (Cárdenas-Arroyo 1995; Groot 1991; Uribe 1977-78, 1986; Uribe y Lleras 1982), si bien en los últimos años se han considerado algunos modelos alternativos de periodización (Langebaek y Piazzini 2003; Lleras et al. 2007). La escasa e intermitente investigación arqueológica de la región no ha permitido aún definir la utilidad de los estilos o complejos como marcadores cronológicos, y si se trata de dos tradiciones alfareras paralelas (Capulí y Partial-Tuza) que existirían desde al menos los siglos V y VIDC. Tampoco hay acuerdo sobre las dispersiones o concentraciones espaciales de cada una de éstas, y si las mismas pueden ser asociadas con los territorios de los grupos étnicos que encontraron los españoles. Pero, para el caso tratado en el presente artículo, con independencia de estos problemas aún no resueltos, en lo que respecta a todos los datos arqueológicos conocidos del ámbito geográfico de la cuenca del Río Guáitara en el departamento de Nariño, estos conjuntos, estilos o complejos alfareros llamados Capulí, Piartal o Tuza no fueron reemplazados o acompañados por cerámica inca o de inspiración incaica. Hyslop (1998:44) sugirió que, en el caso colombiano, la ausencia de cerámica inca "[...] se torna en una evidencia negativa de importancia para definir las fronteras del estado".

Esta ausencia contrasta con la situación del lado ecuatoriano. Al sur del Río Chota-Mira, los conjuntos alfareros locales considerados como tardíos, y dentro de los cuales hay elementos cerámicos Capulí, Piartal o Tuza, si son reemplazados o acompañados por cerámica incaica a partir de fechas que pueden ser asociadas a la entrada de los incas en la sierra norte del Ecuador en los últimos lustros del siglo XV DC (Bray 2003; Meyers 1998 [1976]). En lo que respecta al callejón interandino entre el Río Chota-Mira y el curso alto del Río Guáitara, Meyers (1998:223) menciona pocos casos, conocidos de manera indirecta, en donde se aprecian algunos elementos alfareros incaicos en El Ángel, Pioter y San Gabriel (antiguo pueblo de Tusa).
La arquitectura inca es otra línea de evidencias arqueológicas que es usada con frecuencia como referente de la presencia del Tawantinsuyu y el tipo de control sobre el territorio y las comunidades locales. Sitios con arquitectura inca son bien conocidos en la sierra norte de Ecuador en el sector boreal de la provincia de Pichincha y en toda la de Imbabura. Entre estos se nombran tanto centros administrativos y ceremoniales (Bray 2018; Bray y Echeverría 2014) como pucarás (Plaza Schuller 2006 [1976]). Estas últimas estructuras son importantes porque están asociadas a la presencia militar del Tawantinsuyu y seguramente eran hitos espaciales que reafirmaban el poderío inca en un territorio. Pero, los pucarás también pudieron estar relacionados con una estrategia de contención a actitudes de resistencia y rechazo de las etnias locales a las avanzadas de los incas, como lo propone Plaza Schuller (2006 [1976]:20, 115). Esta situación de inestabilidad y hostilidad de las comunidades en Cayambe y Caranqui ante los incas ha sido documentada también por Bray (2003, 2018; Bray y Echeverría 2014) y Caillavet (2000a).

Pero, mientras en Imbabura, cerca de las actuales Ibarra y Otavaló existe un importante número de fortalezas y pucarás conocidos y documentados arqueológicamente, la situación cambia en el altiplano de Carchi, es decir, en la parte meridional del territorio pasto. Las referencias arqueológicas de pucarás entre el Río Chota-Mira y el curso alto del Guáitara son inexistentes hasta la fecha. El único dato proviene del cronista Cieza de León (2005 [1553]:106-107), cuando menciona un posible pucará usado por los incas cerca de los pueblos de Guaca (o Huaca) y Tusa (actualmente San Gabriel, provincia de Carchi), "[...] de donde daban guerra a los pastos, y salían a la conquista de ellos". El cronista lo llamó "Rumichaca", lo que ha generado cierta confusión porque en el actual puesto fronterizo binacional entre Colombia y Ecuador, varios kilómetros al norte de Guaca y Tusa, existe un lugar que se llama de la misma manera en el cañón que se forma en el alto Guáitara. Pero actualmente se tiene cierta certeza que no se trata del mismo "Rumichaca" (Caillavet 2000a:162; Groot 1991:100; Romoli 1977-78).

La confusión se completa además porque tanto el mismo cronista como otros escritos españoles del periodo Colonial citados en textos de arqueología e historia de la región, mencionan que el "Río Angasmayo" era el límite norte del Tawantinsuyu. La ubicación precisa del mismo no es del todo clara, aunque se ha seguido la idea de Ortiz $(1946,1961)$ que el "Angasmayo" sea el Río Guáitara, o un afluente de este. De ser cierta esta suposición, se apoyaría la idea que una parte de las comunidades de la etnia Pasto estarían iniciando un proceso de relación pacífica con los incas (Landázuri 1995; Salomon 1980, 1988), opinión que no es compartida por Caillavet (2000a:161) o Bray (2018:690), quienes mantienen la idea que todo el conjunto de los pastos opuso resistencia 
al avance incaico. En todo caso, dentro de la discusión quedarían por fuera los pastos de la cuenca del Guáitara en los altiplanos de Ipiales al norte y, dado lo incipiente y poco consolidado del proceso de incorporación de los pastos meridionales al Tawantinsuyu al momento de la conquista española, es difícil encontrar alguna trazabilidad arqueológica del problema. Los argumentos provienen principalmente de evidencia historiográfica.

A nivel del estudio de procesos jurídicos desprendidos de la relación de los indígenas con la administración colonial española, Salomon (1988) encontró una posible inferencia de los incas sobre las actividades de los mindalaes que servían a los caciques de localidades pasto en el altiplano de Carchi. Por su parte, Landázuri (1995) sugiere que entre los cacicazgos pasto del sur había una mayor centralización que entre los del norte, y que esto puede ser el resultado de una actividad mayor de los incas en el sector. Al respecto, los estudios etnográficos y de documentación tardía del periodo Colonial hechos por Rappaport (1988a) entre las comunidades pasto de la zona de Cumbal e Ipiales indican una organización política y territorial con pocos niveles de centralización. La escasa investigación arqueológica realizada en el altiplano sur de Nariño y otras áreas en Río Guáitara sugieren conclusiones similares, en el sentido de observar asentamientos de tipo disperso (Cárdenas y Bernal 2019; Langebaek y Piazzini 2003; Uribe 1986).

Por último, no puede pasar inadvertida la existencia de una serie de construcciones en piedra en el curso altomedio del Río Guáitara en la jurisdicción de los actuales municipios de Iles, Funes e Imues, y de las cuales no se conoce ningún referente comparativo en el resto del territorio nacional de la actual Colombia (Figura 7). Según algunos autores estas construcciones son de origen inca (Calero 1991:37), no obstante, los trabajos arqueológicos realizados allí por Groot a mediados de la década de 1970 (Groot 1991), y en los últimos años como parte del apoyo investigativo al Qhapaq Nan (Groot y Villada 2009), muestran que la cerámica arqueológica con las que se las que se podría asociar espacialmente a estas estructuras es clara e inequívocamente de estilo o complejo Tuza. Hasta la fecha no se ha encontrado cerámica inca o de influencia incaica. Una parte de las construcciones en piedra podrían ser terrazas de cultivo, pero es desconocida la función de otras de éstas. Como la misma autora lo reconoce, hace falta una mayor investigación sobre el sitio, y ciertamente es difícil aún aseverar quienes las hicieron, en qué momento, y para qué fines fueron construidas.

Con estas evidencias se puede especular un poco con la idea que mediante algunas exploraciones los incas

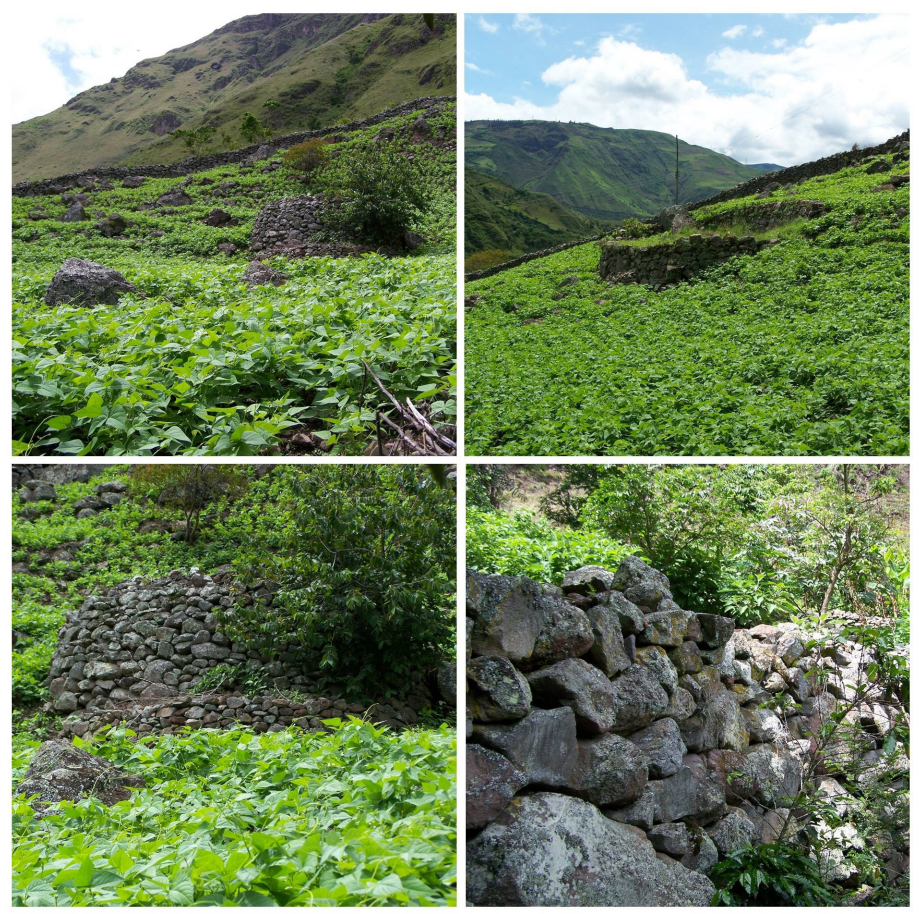

Figura 7. Construcciones en piedra del curso alto-medio del Río Guáitara. Fotos de Alejandro Bernal Vélez.

Stone constructions of the upper-middle course of the Guáitara river. Photos by Alejandro Bernal Vélez. 
estarían intentando un control de la cuenca del Guáitara, cuyas características geográficas y ecológicas se prestan para tener acceso a áreas de cultivo de tubérculos y maíz, así como de coca y algodón. En las páginas anteriores se señaló la importancia estratégica de ríos como el Chota-Mira y el Guáitara para acceder a recursos de áreas de bosque húmedo tropical en los piedemontes occidentales y orientales de la cordillera, y cómo en los altiplanos de Ipiales y Carchi se evidencia una compleja dinámica de intercambio que existían varios siglos antes de cualquier tipo de presencia del Tawantinsuyu. Es posible pensar que los incas buscaran incorporar estas relaciones de intercambio de mediana y larga distancia para su beneficio.

\section{Conclusiones}

La circulación y movimiento de productos entre ecologías diferentes dentro del callejón interandino configuró un sentido del espacio que trascendió el territorio que cada cacicazgo, etnia y unidad política consideraba como propio, además de extenderse el ámbito puramente geográfico y ecológico ya que conectaban la Amazonía, la sierra andina y la llanura del Pacífico. Esta interacción existió varios siglos antes de la llegada de los incas a la sierra norte del Ecuador.

Cieza de León, quien recorrió el callejón interandino de la región de norte a sur, es decir de Pasto e Ipiales con dirección a Cusco, nombra que cerca de Guaca "se ve el camino de los Ingas tan famoso en estas partes" (Cieza de León 2005 [1553]:106-107), lo cual se puede tomar desde la perspectiva colombiana como una referencia del lugar en donde comenzaban las estructuras viales construidas por los incas o que al menos se encontraban transformadas por estos. Bajo las descripciones de los tramos colombianos del Qhapaq Ñan (Groot y Villada 2009; Leguizamón et al. 2019; Universidad de Nariño 2010), no existe claridad aún que estas estructuras tengan una relación técnica o constructiva con el Camino Principal Andino de la misma manera que lo correspondiente a los tramos del centro del Ecuador, o con las vías prehispánicas que discurren entre Quito y el confín de un área de dominación incaica más efectiva en los territorios de Cayambe y Caranqui.

Independientemente de la relación que se pueda establecer entre los caminos históricos encontrados en los Andes del sur de Colombia con aquellos construidos o usados por los incas, es indudable que los sistemas de infraestructura vial y de comunicación fueron agentes materiales que facilitaron el contacto y la interacción entre grupos y comunidades del callejón interandino. Estos gestaron, construyeron y mediaron en las oposiciones "sierra-piedemonte-selva" o "frío""caliente". Expresado en otras palabras, los caminos son elementos fundamentales en la construcción social del espacio andino en el sentido que traspasan y rompen límites, bien sean estos geográficos, ecológicos, étnicos o culturales, haciendo que las fronteras se vuelvan permeables y "fluidas" como lo ha mostrado la antropóloga e historiadora María Clemencia Ramírez $(1992,1996)$ para el caso del piedemonte amazónico de Nariño. Este es uno de los puntos sobre los que repercute una de las mayores valoraciones que puede tener el tema de los caminos y el Qhapaq Nan.

Los indicios sobre la ocupación inca en los Andes Septentrionales comienzan a volverse gradualmente imperceptibles conforme se avanza hacia el norte desde lugares con evidencias de una dominación más efectiva y rastreable como Otavalo e Ibarra. En el artículo se resalta que la dominación inca más al norte del Río Chota-Mira era muy incipiente, endeble y precaria, al punto que la presencia de los incas en la región puede ser irrelevante para entender las dinámicas socioculturales o políticas de las comunidades en ese sector de los Andes Septentrionales.

Quedan por explorarse en futuros trabajos otro tipo de evidencias para entender la relación de los grupos del sur andino de la actual Colombia con la progresiva expansión del Tawantinsuyu, como es la presencia de quechuismos y de hablantes de quechua en el oriente del departamento de Nariño y los piedemontes amazónicos adyacentes a este. En el presente artículo se optó por concentrarse en la relación de las comunidades pasto del callejón interandino con la expansión incaica y el tipo de presencia incaica que se puede rastrear mediante la arqueología y la historiografía del sector.

Parecería prudente por el momento continuar con la idea de Salomon (1980) que todo el conjunto regional de los altiplanos y valles interandinos de los actuales Nariño y Carchi sea considerado como un espacio fronterizo dentro del cual se alternaban sectores de dominación efectiva con un mundo andino no sometido pero relacionado de alguna manera con los incas. Las distintas líneas de evidencia para evaluar la cuestión de la presencia incaica en el sur andino de Colombia se deben considerar mayoritariamente en esta perspectiva y no en la búsqueda del dónde y cuándo se fijó un límite preciso.

Agradecimientos: Deseo expresar mi gratitud al arqueólogo chileno Carlos González Godoy por invitarme a participar tanto en el II simposio sobre el Qhapaq Ñan realizado en Salta (Argentina) en octubre de 2017, como en el simposio sobre caminos que se realizó en el marco del IX TAAS de Ibarra (Ecuador) en junio de 2018. Buena parte de los argumentos e ideas presentadas en este artículo fueron elaborados para su lectura en ambos eventos. Igualmente, agradezco a los evaluadores anónimos del escrito por las anotaciones y sugerencias. Estas contribuyeron a mejorar la calidad del argumento. 


\section{Referencias Citadas}

Bernal, A. 2000. Circulación de productos entre los pastos en el siglo XVI. Arqueología del Área Intermedia 2:125-152.

Bernand, C. 2008. Cerros, nevados y páramos: un intento de arqueología etnográfica. Revista Española de Antropología Americana 38 (1):167-189.

Bonavia, D. 1996. Los Camélidos Suramericanos: Una Introducción a su Estudio. Instituto Francés de Estudios Andinos, Lima.

Bray, T.L. 2003. Los Efectos del Imperio Incaico en la Frontera Septentrional: Una Investigación Arqueológica. Ediciones Abya-Yala, Quito.

Bray, T.L. 2018. Al final del imperio: avances imperiales en la frontera norte. En El Imperio Inka, editado por I. Shimada, pp. 672-712. Fondo Editorial de la Pontificia Universidad Católica del Perú, Lima.

Bray, T.L. y J. Echevarría 2014. Al final del imperio: el sitio arqueológico Inca-Caranqui en la sierra septentrional del Ecuador. Antropología, Cuadernos de Investigación 13:127150.

Caillavet, Ch. 2000a. La frontera septentrional del imperio inca. En Etnias del Norte. Etnohistoria e Historia del Ecuador, pp. 159-174. Casa de Velázquez - Instituto Francés de Estudios Andinos - Ediciones Abya-Yala, Quito.

Caillavet, Ch. 2000b. La geografía sagrada del Otavalo Prehispánico. En Etnias del Norte. Etnohistoria e Historia del Ecuador, pp. 397424. Casa de Velázquez - Instituto Francés de Estudios Andinos - Ediciones Abya-Yala, Quito.

Caillavet, Ch. 2000c. Las técnicas agrarias autóctonas y la remodelación colonial del paisaje. En Etnias del Norte. Etnohistoria e Historia del Ecuador, pp. 123-138. Casa de Velázquez - Instituto Francés de Estudios Andinos - Ediciones Abya-Yala, Quito.

Calero, L. F. 1991. Pastos, Quillacingas y Abades 1535-1700. Banco Popular, Bogotá.

Cardale de Schrimpff, M. 1977-78. Textiles arqueológicos de Nariño. Revista Colombiana de Antropología 21:245-282.

Cárdenas-Arroyo, F. 1995. Complejos cerámicos como marcadores territoriales: el caso crítico del Piartal-Tuza en la arqueología de Nariño. En Perspectivas Regionales en la Arqueología del Suroccidente de Colombia y Norte del Ecuador, editado por C. Gnecco, pp. 49-58. Editorial Universidad del Cauca, Popayán.

Cárdenas-Arroyo, F. y A. Bernal 2019. Excavaciones arqueológicas en el Valle de Atríz y el Cañón del río Guáitara. En Investigaciones Arqueológicas en Nariño. Altiplano de Ipiales, Cañón del Río Guáitara, Valle de Atríz, editado por A. Bernal y F. Cárdenas-Arroyo, pp. 180-282. Instituto Colombiano de Antropología e Historia, Bogotá.

Cavelier, I., A. Bernal, F. Cárdenas-Arroyo y F. Montejo 2019. Excavaciones arqueológicas en Ipiales. En Investigaciones Arqueológicas en Nariño. Altiplano de Ipiales, Cañón del Río Guáitara, Valle de Atríz, editado por A. Bernal y F. CárdenasArroyo, pp. 8-179. Instituto Colombiano de Antropología y Cultura, Bogotá.

Cieza de León, P. 2005 [1553]. Crónica del Perú y el Señorío de los Incas. Biblioteca Ayacucho, Caracas.

Cortés, H.D. 2014. El Qhapaq Ñan en Colombia, los nuevos caminos del patrimonio. Boletín de Historia y Antigüedades 101 (859):453-471
Criado, F. 1991. Construcción social del espacio y reconstrucción arqueológica del paisaje. Boletín de Antropología Americana 24:5-29.

Deler, J.P. 1996. Tiempos y espacios de una horogénesis: los territorios fronterizos entre Colombia y Ecuador. En Frontera y Poblamiento: Estudios de Historia y Antropología de Colombia y Ecuador, compilado por Ch. Caillavet y X. Pachón, pp. 23-40. Instituto Francés de Estudios Andinos - Instituto Amazónico de Investigaciones Científicas (SINCHI)- Universidad de los Andes, Bogotá.

Dillehay, T.D. y P. Netherly 1998 Introducción. En La Frontera del Estado Inca, editado por T.D. Dillehay y P. Netherly, pp. 3-32. Fundación Alexander von Humboldt - Editorial AbyaYala, Quito.

Dillehay, T. D. y A. Gordon 1998. La actividad prehispánica de los incas y su influencia en la Araucanía. En La Frontera del Estado Inca, editado por T. D. Dillehay y P. Netherly, pp. 183-196. Fundación Alexander von Humboldt - Editorial Abya-Yala, Quito.

Dollfus, O. 1981. El Reto del Espacio Andino. Instituto de Estudios Peruanos, Lima.

Doyón, L. 1995. La secuencia cultural Carchi-Nariño vista desde Quito. En Perspectivas Regionales en la Arqueología del Suroccidente de Colombia y Norte del Ecuador, editado por C. Gnecco, pp. 59-84. Editorial Universidad del Cauca, Popayán.

Garcilaso de la Vega, I. 1975 [1609]. Comentarios Reales. Tomo II. Biblioteca Ayacucho, Caracas.

Gómez, A. 1997. Bienes, rutas e intercambio (siglos XV-XIX): las relaciones de intercambio interétnico entre las tierras bajas de la amazonia y las tierras altas de los andes. Revista de Antropología y Arqueología 9 (1-2):50-51.

Groot, A.M. 1991. Territorios y grupos étnicos. En Intento de Delimitación del Territorio de los Grupos Étnicos Pastos y Quillacingas en el Altiplano Nariñense, editado por A.M. Groot y E. M. Hooykaas, pp. 71-160. Fundación de Investigaciones Arqueológicas Nacionales (FIAN), Bogotá.

Groot, A.M. y D.C. Villada 2009. El Camino Principal Andino Qhapaq Nan-desde la arqueología del valle medio del río Guáitara, altiplano sur de Nariño. Informe inédito presentado a Fundación de Investigaciones Arqueológicas Nacionales (FIAN), Bogotá.

Guhl, E. 1975 Colombia: Bosquejo de su Geografía Tropical. Tomo 1. Biblioteca Básica Colombiana. Colcultura, Bogotá.

Hyslop, J. 1998. Las fronteras estatales externas del Tawantinsuyu. En La Frontera del Estado Inca, editado por T.D. Dillehay y P. Netherly, pp. 33-51. Fundación Alexander von Humboldt Editorial Abya-Yala, Quito.

Landázuri, C. 1995. Los Curacazgos Pastos Prehispánicos: Agricultura y Comercio, Siglo XVI. Banco Central del Ecuador Instituto Otavaleño de Antropología - Ediciones Abya-Yala, Quito.

Langebaek, C.H. 1991. Mindalaes, Balsas y la relevancia del imperialismo inca en el sur de Colombia. Cepedesia 18 (61):73-92

Langebaek, C.H. y C.E. Piazzini 2003. Procesos de Poblamiento en Yacuanquer Nariño. Una Investigación Arqueológica sobre la Microverticalidad en los Andes colombianos (Siglos X-XVIII d.C.). Universidad de los Andes - Interconexión Eléctrica Nacional S.A (ISA) - Centro de Estudios Sociales (CESO, Bogotá.

Lefebvre, H. 1974. La producción social del espacio. Papers. Revista de Sociología 3:219-229. 
Leguizamón, L.P., C. Afanador y G. Sánchez 2019. Qhapaq Ñan, Sistema vial andino. En Áreas Arqueológicas Protegidas de Colombia, editado por L.P. Leguizamón, pp. 288-299. ICANH - ANH, Bogotá.

Lleras, R., Gómez, L.A. y J. Gutiérrez 2007. El tiempo en los andes del norte de Ecuador y sur de Colombia: un análisis de la cronología a la luz de nuevos datos. Boletín del Museo Chileno de Arte Precolombino 12 (1):61-83.

López, C.L. 1996. Pueblos del Valle de Atriz. Actuales habitantes del antiguo territorio Quillacinga. En Geografía Humana de Colombia. Tomo IV, Volumen 1. Región Andina Central, editado por F. Correa, pp. 221-273. Instituto Colombiano de Cultura Hispánica, Bogotá.

Mamián, D. 1996. Los pastos. En Geografía Humana de Colombia. Tomo IV, Volumen 1. Región Andina Central, editado por F. Correa, pp. 9-118. Instituto Colombiano de Cultura Hispánica, Bogotá.

Meyers, A. 1998 [1976]. Los Incas en el Ecuador. Análisis de los Restos Materiales. Tomo I. Ediciones Abya-Yala - Banco Central del Ecuador, Quito.

Molestina, M.C. 1998. Transferencias ideológicas en la Sierra Norte (Ecuador). En El Área Septentrional Andina. Arqueología y Etnohistoria editado por M. Guinea, J. Marcos y F. Bouchard, pp. 235-255. Ediciones Abya-Yala - Instituto Francés de Estudios Andinos, Quito.

Morris, C. 1998. Más allá de las fronteras de Chincha. En $L a$ Frontera del Estado Inca, editado por T.D. Dillehay y P. Netherly, pp. 106-113. Fundación Alexander von Humboldt - Editorial Abya-Yala, Quito.

Oberem, U. 1981. El acceso a recursos naturales de diferentes ecologías en la sierra ecuatoriana (siglo XVI). En Contribución a la Etnohistoria Ecuatoriana, editado por S. Moreno y U. Oberem, Tomo I, pp. 45-71. Instituto Otavaleño de Antropología, Otavalo.

Ortiz, S.E. 1961. A propósito del límite septentrional del imperio incaico. Boletín Cultural y Bibliográfico 4 (1):3-6.

Ortiz, S.E. 1946. The Native Tribes and Lenguages of Southwestern Colombia. En Handbook of South American Indians, editado por J.H. Steward, Volume 2, pp. 911-914. The Andean Civilizations, Smithsonian Institution - Bureau of American Ethnology, Washington D.C.

Parsons, J.J. 1982. The Northern Andean Environment. Mountain Research and Development 2 (3):253-264

Plaza Schuller, F. 2006 [1976]. La incursión Inca en el septentrión ecuatoriano. Revista Sarance, serie Monografías 2:17-139.

Plazas, C. 1977-78. Orfebrería prehispánica del Altiplano Nariñense, Colombia. Revista Colombiana de Antropología 21:197-244.

Rappaport, J. 1988a. La organización socio-territorial de los pastos: una hipótesis de trabajo. Revista de Antropología 4 (2):71-106

Rappaport, J. 1988b. Relaciones de intercambio en el sur de Nariño. Boletín del Museo del Oro 22:33-53.
Ramírez de Jara, M.C. 1992. Los quillacinga y su posible relación con grupos prehispánicos del oriente ecuatoriano. Revista Colombiana de Antropología 29:28-61.

Ramírez de Jara, M.C. 1996. Frontera Fluida entre Andes, Piedemonte y Selva: El caso del Valle del Sibundoy, Siglos XVI - XVIII. Cuadernos de Historia Colonial IV. Instituto de Cultura Hispánica, Bogotá.

Reichel-Dolmatoff, G. 1977. Las bases agrícolas de los cacicazgos Sub-Andinos de Colombia. En Estudios Antropológicos, editado por G. Reichel-Dolmatoff y A. Dussán, pp. 23-48. Colcultura, Bogotá.

Rincón, L.S. 2001. Camélidos domésticos en el Altiplano de Carchi-Nariño, Siglo XI d.C. En Memorias del Simposio Pueblos y Ambientes: Una Mirada al Pasado Precolombino, editado por G. Mortcote, pp. 95-100. Academia Colombiana de Ciencias Exactas Físicas y Naturales - Universidad de los Andes, Bogotá.

Rodicio, S. 1996. Los cultivos y aprovechamiento en Popayán, Pasto y zonas adyacentes en el siglo XVI. En Cultura y Medio Ambiente en el Área Andina Septentrional, editado por M. Guinea, J.F Bouchard y J. Marcos, pp. 67-98. Ediciones Abya-Yala, Quito

Romoli, K. 1977-78. Las tribus de la antigua jurisdicción de Pasto en el Siglo XVI. Revista Colombiana de Antropología 21:11-55

Salomon, F.V. 1980. Los Señores Étnicos de Quito en la Época de los Incas. Instituto Otavaleño de Antropología, Otavalo.

Salomon, F.V. 1988. Un complejo de mercaderes en el norte andino bajo la dominación de los incas. Revista de Antropología 4 (2):107-126.

Salomon, F. V. 1998. Frontera aborigen y dualismo inca en el Ecuador Prehispánico: pistas onomásticas. En La Frontera del Estado Inca, editado por T. D. Dillehay y P. Netherly, pp. 52-70. Fundación Alexander von Humboldt - Editorial Abya-Yala, Quito.

Stahl, P. 2003. Precolumbian andean animal domesticates al the edge of empire. World Archaeology 34 (3):470-483.

Troll, C. 1958 [1943]. Las culturas superiores andinas y el medio ambiente geográfico. Traducido por C. Nicholson. Revista del Instituto de Geografía 5:3-49

Universidad de Nariño 2010. Qhapaq Ñan -Camino Principal Andino- Colombia. Informe General presentado a Unesco por el Equipo Técnico de Investigación Qhapaq Nan Colombia. Universidad de Nariño, Pasto.

Uribe M.V. 1977-78. Asentamientos prehispánicos en el Altiplano de Ipiales Colombia. Revista Colombiana de Antropología 21:57-195

Uribe M.V. 1986. Pastos y protopastos: la red regional de intercambio de productos y materias primas de los siglos X a XVI d.C. Maguaré 3:33-45

Uribe, M.V. y R. Lleras 1982-83. Excavaciones en los cementerios Protopasto de Miraflores, Nariño. Revista Colombiana de Antropología 24:335-379. 